\title{
Sense and Thought
}

\section{A Study in Mysticism BY GRETA HORT}

"A fresh and illuminating analysis of the mental development of a mystic."-Time and Tide

"Dr. Hort's book is a careful, detailed, and scholarly study, and everyone who is interested in mysticism ought to read it."-Methodist Recorder.

8s. $6 d$.

\section{Kant's Metaphysic of Experience By H. J. PATON}

A detailed commentary on the first half of the Critique of Pure Reason. It deals with Kant's positive metaphysics, his account of what we know about the universal and necessary characteristics of the world experienced by us as human beings.

Library of Philosophy. 2 vols. 30s. the set

\section{George Allen \& Unwin Ltd.}

\section{MANCHESTER COLLECE, OXFORD}

(Founded in Manchester 1786)

SENIOR THEOLOGICAL STUDENTSHIPS.

The Governing Body of Manchester University, and must provide evidence College proposes to elect One or Two Theological Research Students if suitable Candidates present themselves.

The Studentships will be of the annual value of $f_{300}$. They will be tenable for two years but may be renewed for a third year at the discretion of the College. Candidates must be graduates of an approved

(a) of their academical qualifications, and

(b) of their ability to undertake original research in Theology.

The Studentships are open to men or women of any sect, creed, race, or colour.

Applications to be sent to the Principal, Manchester College, Oxford; from whom copies of the Prospectus of the College may be obtained.

\section{SCIENTIFIC BOOKS}

Works in all branches of Science, English and Foreign, including PHILOSOPHY, supplied from stock, or obtained promptly to order. Catalogues of new books of all publishers post free on request.

\section{H. K. LEWIS \& Co. Ltd.}

\section{Gower Street Tel. Euston 4282 London, W.C.1}




\section{Objective Evolution}

BY C. PLEYDELL-BOUVERIE Author of "The Cosmic Awakening"

The latest indications of science are combined to form a synthesis illustrative of the evolution of creative consciousness and its effects as manifested in the development of civilisation.

$7 / 6$ net

Williams \& Norgate Ltd. Gt. Russell Street, London

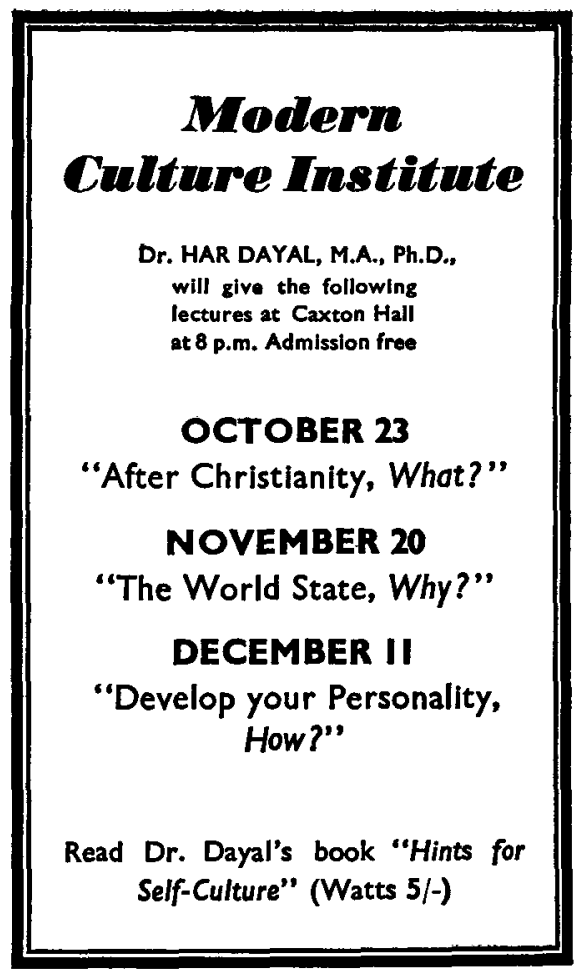

"After Christianity, What?"

NOVEMBER 20

"The World State, Why?"

DECEMBER II

How?"

Self-Culture" (Watts 5/-)

\section{Socioldgical $\boldsymbol{I C} \boldsymbol{e} \boldsymbol{i} \boldsymbol{e}$}

Editorial Board:

A. M. Carr-Saunders, Alexander Farquharson Morris Ginsberg

The Sociology of Pareto

Morris Ginsberg

The Recruitment of the Nation's Leaders

E. L. Clarke

Further Historical Evidence for the Growth of the Chinese Population

Social Surveys and Sociology C. P. Fitzgerald

The Factory Worker's Philosophy

A. F. Wells

Ferdinand Tönnies

M. G. Dickson

Karl Mannheim

THE LePLAY HOUSE PRESS, 35 Gordon Square, London, W.C.I. ANNUAL SUBSCRIPTION, $E 1$ 1s. Od., post free. Single copies 5 s. 